\title{
A DECISION TREE APPROACH FOR ACHIEVING HIGH CUSTOMER SATISFACTION AT URBAN INTERCHANGES
}

\author{
Maria Tsami', Giannis Adamos ${ }^{2}$, Eftihia Nathanail', \\ Evelina Budilovich (Budiloviča) ${ }^{4}$, Irina Yatskiv (Jackiva) ${ }^{5}$,Vissarion Magginas ${ }^{6}$
}

\author{
${ }^{1}$ University of Thessaly, Department of Civil Engineering \\ Pedion Areos, GR-38334 Volos, Greece \\ Ph.: +302421074133, Fax: +302421074131, E-mail: marttsami@gmail.com \\ ${ }^{2}$ University of Thessaly, Department of Civil Engineering \\ Pedion Areos, GR-38334 Volos, Greece \\ Ph.:+302421074158, Fax: +302421074131,E-mail: giadamos@civ.uth.gr \\ ${ }^{3}$ University of Thessaly, Department of Civil Engineering \\ Pedion Areos, GR-38334 Volos, Greece \\ Ph.: +302421074164, Fax: +302421074131, E-mail: enath@uth.gr \\ ${ }^{4}$ Transport and Telecommunication Institute \\ Lomonosova Street 1, LV-1019 Riga, Latvia \\ Ph.: +37167100544, Fax:+37167100660, E-mail: evelina.budilovich@gmail.com \\ ${ }^{5}$ Transport and Telecommunication Institute \\ Lomonosova Street 1, LV-1019 Riga, Latvia \\ Ph.: +37167100544, Fax:+37167100660,E-mail: Jackiva.I@tsi.lv \\ ${ }^{6}$ University of Thessaly, Department of Civil Engineering \\ Pedion Areos, GR-38334 Volos, Greece \\ Ph.: +302421074133, Fax: +302421074131,E-mail:amagginas@yahoo.gr
}

This paper introduces a decision tree approach, which can be used for the assessment of the design, operation and services provided at urban transport interchanges. Realizing a customer satisfaction survey, feedback was received from 239 users of the Riga International Coach Terminal on crucial attributes, including: travel information, wayfinding information, time and movement, access, comfort and convenience, station attractiveness, safety and security, emergency situation handling and overall satisfaction. Findings revealed the most significant parameters that need to be addressed in order to increase users' satisfaction, which can gradually improve the overall attractiveness of the terminal and the efficient provision of its services.

Keywords: City hubs; operation; design; evaluation; decision making; sustainability; public transport; intermodality

\section{Introduction}

According to the Transport White Paper (European Commission, 2001), mobility is very important for the internal market and the quality of life of people. Parameters, such as accessibility, reliability and quality that affect transport services, will gain significant importance in the next years due to aged population growth, urban sprawl and the need to promote public transport (Ewing et al., 2008; Vuchic, 2005).

An interchange is a transport-transfer hub created to gather and distribute passengers as efficiently as possible by linking outward-bound urban passenger transport facilities, such as railway stations, airports, coach stations, or port terminals, as well as various inner-city transport systems, including subways, buses, taxis, and cars. People-oriented amenities and services, i.e. restaurants, cafes and Internet connectivity that make travelling more enjoyable should also be addressed by new interchanges. Crucial characteristics of interchanges can be considered the following (ADB, 2015):

- Size differences of interchange hubs, affected by the volume of passenger flow, the different transportation modes and the role of the hubs in the local and regional area.

- Gateway to the city: an interchange hub is the gateway to the city, serving both as an access point and as a driver of mixed-use development, and functioning as a vital factor of the city's urbanization process.

- Transport integration and high-density development: modern interchanges link different transport modes in one location, improving at the same time land use efficiency. Each transport 
mode supports the other by facilitating the redistribution of passenger overloads among them and catering passenger requirements. Hubs can also provide commercial and retail facilities and can be linked with mixed-use development in the surrounding area.

- The driver of regional economic development.

- Period of interchange hub development: the development of an interchange hub requires a relatively long period from the planning stage to construction, until its full operation. Lengthy time scales of development affect the overall transport system and especially for those people living in the surrounding areas.

- Spatial range of influence: the interchange hub has both direct and indirect areas of influence on the neighbourhood, where it is located. Directly, the hub affects transport services, meaning that travel can be completed using the transport network of the interchange hub, resulting in convenient traffic conditions (i.e. duration, distance, number of transfers). On the other hand, the area of indirect influence covers a wider area, which is not directly connected with the respective transport network.

Travel enabling, interchange as a facility and accessibility to/from the interchange are the three main categories which aggregate the requirements and expectations of travelers, related to accessibility and available facilities. Nathanail et al. (2016) suggested that crucial quality parameters can enhance the efficiency of an interchange are travel time, punctuality and reliability, integrated servicing, comfort and convenience and safety and security.

The aim of this paper is to assess the performance of the Riga's International Coach Terminal (RICT) through a decision tree approach, formulated by the overall satisfaction level and a number of indicators, grouped under eight criteria: travel information, wayfinding information, time and movement, access, comfort and convenience, station attractiveness, safety and security and emergency situation handling.

RICT, cooperating with 30 passenger transportation companies (16 of which ensure domestic transportation, 18 international transportation, and 12 of them are foreign companies) is one of the most important transport interchanges in Latvia. On average, the terminal maintains 420 routes daily, 350 of which are domestic and 70 are international routes, serving more than 2 million passengers (RD PAD, 2017).

The rest of the paper is structured as follows: in Chapter 2, a state-of-the-art analysis is presented, focusing on decision trees and transport service quality. The methodology of the paper is given in Chapter 3, followed by the presentation of results in Chapter 4. Lastly, Chapter 5 provides conclusions and reflections about possible implications for the future research.

\section{State-of-the-art analysis}

\subsection{Decision trees}

Decision trees are decision making support tools that are used in data mining and artificial intelligence research and visualize the decision making process in the form of tree-shaped structures. In these structures there are three kinds of nodes. The first node (root node) represents the basic criterion of the decision making procedure and is where the first branches of the structure are created, the inner (chance) nodes represent specific criteria or requirements, which based on their fulfilment by the items under consideration, form the rest of the branches of the decision tree, and the nodes found at the lowest level of the tree (leaf nodes) represent the possible final outcomes of the process based on the different combinations of fulfilled criteria or requirements (Allmuali et al., 2002; Kumar, 2014; Song and Lu, 2015).

The construction of a decision tree model requires a dataset of objects and a vector of attributes providing information about this dataset's objects. The objects are then subjected to tests with mutually exclusive outcomes based on their attributes. This process begins at the root node, continues at the inner nodes and is responsible for the creation of the decision tree's nodes and branches. After each test, the dataset is divided into subsets the objects of which have given the same outcome. This process is repeated until final subsets are created, the objects of which have the same attributes and no further division is possible. These final subsets are the leaf nodes of the decision tree (Allmuali et al., 2002; Kumar, 2014).

Decision tree models can be used to select the number and kind of variables required for the conduct of a research, assess the relative importance of these variables, handle any missing values in a dataset, predict outcomes based on past data and improve the handling of categorical variables by allowing the researcher to merge categories when their number is too high (Song and Lu, 2015).

Decision trees also have a lot of practical applications throughout a multitude of disciplines. They have been used in cases where decisions have to be made regarding the approval of a business project or 
the issue of insurance policies (Kumar, 2014), as well as in library science, chemistry, medicine and physics (Allmuali et al., 2002).

\subsection{Decision trees and transport service quality}

Decision trees have also been used in relation with transport service quality. More specifically, the J48 algorithm was used to formulate a decision tree which, taking into consideration users' perception and expectations, assessed the importance and performance of transport quality of service indicators based on data collected through a customer satisfaction survey conducted in Greece (Tsami and Nathanail, 2016). Another case of decision trees used for transport quality of service assessment, is the use of the CART (Classification and Regression Tree) method to identify key performance indicators of transport service quality, making use of data that were collected during a customer satisfaction survey directed at the users of Granada's public transportation system (de Ona et al., 2011). The CART method was also used in conjunction with cluster analysis to analyze the transit quality of service and identify the most important quality of service factors taking into account users' preferences. The data were collected from four customer satisfaction surveys commissioned by the Transport Consortium of Granada and the researchers identified four different customer clusters based on their preferences. Subsequently, a decision tree was created for each cluster, as well as one for the entire sample to determine the importance and classify the quality of service attributes for each customer cluster and identify the most important of these attributes across the whole sample (de Ona et al., 2016).

\subsection{J48 classifier}

The J48 classifier is a decision tree implementation of $\mathrm{C} 4.5$ algorithm in the open source software WEKA (Waikato Environment for Knowledge Analysis) (Acharia et al., 2015; Ahishakive et al., 2017; Gao et al., 2013; Kapoor and Rani, 2015; Kaur and Chhabra, 2014; Patil and Sherekar, 2013). The C4.5 algorithm is an extension of Quinlan's previous ID3 algorithm (Ahishakive et al., 2017) and uses the concept of information gain ratio to determine the attribute based on which the testing of the dataset's objects and its division into subsets will happen during the previously mentioned recurring process (Gao et al., 2013). In few words, the algorithm (C4.5) learns a mapping from attribute values to classes, applied to classify new, unseen instances. Beginning with the root node that represents the entire dataset the algorithm splits data into smaller subsets that denote the partitions of the original dataset that satisfy specified attribute value tests. This process continues until all instances in the subset fall in the same class and therefore the tree growing is terminated (Breiman et al., 1984; Quinlan, 1993).

The C4.5 algorithm and its J48 WEKA version have been used in a wide range of cases across many disciplines. An improved version of the algorithm has been used to estimate the performance of university students (Gao et al., 2013). Another improved version of the J48 classifier was used for the prediction of diabetes through the use of patients' medical records (Kaur and Chhabra, 2014). J48 has also been used for the identification of water bodies (Acharia et al., 2015) and the prediction of crime rates (Ahishakive et al., 2017), as well as for the determination of the quality of contaminated water, where the J48 tree was compared with five other classification methods with very good results (Dota et al., 2015) and emotion recognition (Yan et al., 2015). In terms of quality of service, J48 has been mainly used to determine the quality of service of web based services based on quality attributes (Vaadaaka et al., 2013).

$\mathrm{J} 48$ has been found to be one of the most reliable decision tree models, as well as a reliable classification method when compared to different approaches.

Indicatively, in a study testing different classification methodologies (k-NN, C4.5, Naive Bayes, $\log$, Linear Classifier and SVM) across datasets with different characteristics, it was shown that J48's C4.5 algorithm was efficient in correctly classifying the data in every case and when the results of the test were represented graphically, C4.5 had one of the highest Area Under Curve (UAC) values in all of the cases (Maleki-Entezari et al., 2009).

\section{Methodology}

\subsection{Data collection}

For the data collection, a questionnaire survey was designed and implemented both online and face-to-face. The questionnaire was divided into three parts. The first one consisted of general trip information questions, such as origin and destination, trip stage, travel purpose, trip duration and means of transport used to travel to and from the terminal. The second part was dedicated to passenger 
satisfaction questions. In this part passengers were required to rate a number of indicators in a Likert scale (1-5), with 1 being the lowest possible score and 5 being the highest. The last part included questions about the status of respondents, addressing gender, age, education level, employment status and netincome per month. For the purpose of this particular study the questionnaire was also translated into Latvian and Russian.

\subsection{Data analysis}

Data were analyzed through descriptive and inferential statistics. In the first case, a number of the sample demographic characteristics were addressed by estimating the frequency distribution per characteristic, as well as the mean values and standard deviations. In the second case, the statistical analysis of the responses was carried out using non-parametric tests. Specifically, in order to investigate the inter-relationships among the several indicators, bivariate correlations were conducted (Spearman test). A confidence level of $95 \%$ and confidence interval of $5 \%$ were assumed.

A decision tree was used to model how the performance evaluation of the selected indicators affects the overall satisfaction level of the terminals. The goal is to have satisfied users and therefore it is crucial to indicate all these elements that lead to a high level of overall satisfaction. In this study, the Weka J48 tree was used, as an open Java implementation of the C4.5 algorithm.

In total 37 indicators (Table 1) were analyzed using the J48 classifier tree with the pruning values of 0.25 and as test mode the evaluation on training data. The developed tree had 51 nodes and 26 leaves (end nodes).

\section{Results}

\subsection{Sample characteristics}

The survey, organized by the Transport and Telecommunication Institute in cooperation with Riga's International Coach Terminal, was realized in Spring 2017. Achieving a response rate of 95\%, the final sample was determined to 239 users.

The $62 \%$ of the respondents are women and the rest $38 \%$ men. The $35 \%$ of the users are between 18-25 years old, the $30 \%$ of them - between $41-65$, the $28 \%$ - between $26-40$, the $3 \%$ of them younger than 17, the $3 \%$ older than 66 years old, and the rest $1 \%$ preferred not to answer this question. Regarding the education level of the respondents, it was observed that the majority of them (55\%) is highly educated, the $24 \%$ has received secondary level of education, the $15 \%$ holds a secondary professional level diploma, and the rest $6 \%$ are primarily educated.

Most respondents (41\%) live in households with 1-2 people, the $22 \%$ in households with 3 people and the rest $37 \%$ in households with more than four people. Focusing on the employment status of respondents, it was observed that the $64 \%$ of them are employed, the $24 \%$ are students, the $3 \%$ are unemployed and the rest $9 \%$ respondents stated a different status. Lastly, regarding the monthly netincome of respondents, the $28 \%$ of them have income $200-499$ EUR, the $27 \% 500-799$ EUR, the $28 \%$ greater than $800 \mathrm{EUR}$, and the rest $17 \%$ lower than $200 \mathrm{EUR}$.

\subsection{Evaluation of users' satisfaction level}

The results of the evaluation of the 37 indicators by the terminal users are presented in Table 1, which shows the average rating (M) and the standard deviation (SD) in columns 4 and 5, respectively. Results showed that users were mostly highly or moderately satisfied with the majority of the features and services related to the terminal's accessibility level: "Ease of access from the interchange" (M=4.02, standard deviation $\mathrm{SD}=0.93)$ and "Ease of access to the interchange" $(\mathrm{M}=3.97, \mathrm{SD}=0.94)$. The criterion "Travel information", addressed by four individual indicators also received high rating. For example, respondents consider that the available information for ticket purchase is more than adequate $(\mathrm{M}=4.01$, $\mathrm{SD}=1.0$ ).

On the other hand, travellers seem not to be satisfied with the station design, since the indicators describing "Station attractiveness" received the lowest rating: "The internal design of the terminal" $(\mathrm{M}=2.81, \mathrm{SD}=1.16)$, "The external design of the terminal" $(\mathrm{M}=2.91, \mathrm{SD}=1.15)$ and "The surrounding area is pleasant" $(\mathrm{M}=2.93, \mathrm{SD}=1.17)$.

In addition, the correlation degree among the individual indicators and their relationships with the criterion satisfaction level was investigated, and measured by the Spearman correlation coefficient (Column 6). In this case, it was observed that the indicators that mostly affect positively the overall 
satisfaction of users seem to be: "The internal design of the terminal" $(\beta=0.675, p$-value $<0.05)$, "The surrounding area is pleasant" $(\beta=0.674$, $p$-value $<0.05)$, "Safety getting on and off the transport mode" $(\beta=0.639$, $p$-value $<0.05)$, "The external design of the terminal" $(\beta=0.635, p$-value $<0.05)$ and "Safety whilst inside the terminal" $(\beta=0.630$, $p$-value $<0.05)$.

Table 1. Evaluation of indicators

\begin{tabular}{|c|c|c|c|c|c|}
\hline Criteria & Indicators & Code & $\begin{array}{l}\text { Average } \\
\text { rating (M) }\end{array}$ & $\begin{array}{c}\text { Standard } \\
\text { deviation } \\
\text { (SD) }\end{array}$ & $\begin{array}{c}\text { Spearman } \\
\text { correlation } \\
\text { coefficient }\end{array}$ \\
\hline \multirow{4}{*}{$\begin{array}{l}\text { Travel } \\
\text { information }\end{array}$} & $\begin{array}{l}\text { Availability and ease of use of travel } \\
\text { information at the terminal }\end{array}$ & A1 & 3.97 & 0.94 & $0.474 *$ \\
\hline & $\begin{array}{l}\text { Availability of travel information (timetables, } \\
\text { routes, delays) before your trip }\end{array}$ & A2 & 3.95 & 1.00 & $0.452 *$ \\
\hline & $\begin{array}{l}\text { Accuracy and reliability of travel information } \\
\text { displays for bus/trains at the terminal }\end{array}$ & A3 & 3.96 & 0.92 & $0.531 *$ \\
\hline & $\begin{array}{l}\text { Ticket purchase (ticket offices, ticket } \\
\text { machines, etc.) }\end{array}$ & A4 & 4.01 & 1.0 & $0.416^{*}$ \\
\hline \multirow{3}{*}{$\begin{array}{l}\text { Wayfinding } \\
\text { information }\end{array}$} & Signposting to different facilities and services & B1 & 3.62 & 1.05 & $0.492 *$ \\
\hline & $\begin{array}{l}\text { Signposting to transfer between transport } \\
\text { modes in all parts of the terminal }\end{array}$ & B2 & 3.31 & 1.12 & $0.557 *$ \\
\hline & Information and assistance provided by staff & B3 & 3.59 & 1.08 & $0.516^{*}$ \\
\hline \multirow{5}{*}{$\begin{array}{l}\text { Time and } \\
\text { movement }\end{array}$} & $\begin{array}{l}\text { Transfer distances between different transports } \\
\text { modes }\end{array}$ & $\mathrm{C} 1$ & 3.77 & 0.97 & $0.377 *$ \\
\hline & $\begin{array}{l}\text { Co-ordination between different transport } \\
\text { operators or transport services }\end{array}$ & $\mathrm{C} 2$ & 3.43 & 1.03 & $0.453^{*}$ \\
\hline & $\begin{array}{l}\text { Use of your time (transferring \& waiting) at } \\
\text { the terminal }\end{array}$ & $\mathrm{C} 3$ & 3.52 & 1.06 & $0.606^{*}$ \\
\hline & Distance between the facilities and services & $\mathrm{C} 4$ & 3.93 & 1.00 & $0.507 *$ \\
\hline & $\begin{array}{l}\text { Ease of movement due to number of people } \\
\text { inside the terminal }\end{array}$ & $\mathrm{C} 5$ & 3.64 & 1.06 & $0.488 *$ \\
\hline \multirow{2}{*}{ Access } & Ease of access to the terminal & D1 & 3.97 & 0.94 & $0.472 *$ \\
\hline & Ease of access from the terminal & D2 & 4.02 & 0.93 & $0.486^{*}$ \\
\hline \multirow{10}{*}{$\begin{array}{l}\text { Comfort and } \\
\text { convenience }\end{array}$} & General cleanliness of the terminal & E1 & 3.28 & 1.15 & $0.591 *$ \\
\hline & $\begin{array}{l}\text { Temperature, shelter from rain and wind, } \\
\text { ventilation, air conditioning }\end{array}$ & E2 & 3.58 & 1.09 & $0.622 *$ \\
\hline & General level of noise of the terminal & E3 & 3.39 & 1.05 & $0.521 *$ \\
\hline & $\begin{array}{l}\text { Air quality, pollution (e.g. emissions from } \\
\text { vehicles) }\end{array}$ & E4 & 3.20 & 1.12 & $0.539 *$ \\
\hline & Number and variety of shops & E5 & 3.13 & 1.17 & $0.512 *$ \\
\hline & $\begin{array}{l}\text { Number and variety of coffee-shops and } \\
\text { restaurants }\end{array}$ & E6 & 3.07 & 1.25 & $0.578^{*}$ \\
\hline & Availability of cash machines & E7 & 3.46 & 1.13 & $0.519 *$ \\
\hline & Availability of seating & E8 & 3.17 & 1.2 & $0.487 *$ \\
\hline & Availability of mobile phone signal and Wi-Fi & E9 & 3.63 & 1.22 & $0.583^{*}$ \\
\hline & $\begin{array}{l}\text { Comfort due to the presence of information } \\
\text { screens }\end{array}$ & E10 & 3.56 & 1.04 & $0.562 *$ \\
\hline \multirow{3}{*}{$\begin{array}{l}\text { Station } \\
\text { attractiveness }\end{array}$} & The surrounding area is pleasant & F1 & 2.93 & 1.17 & $0.674 *$ \\
\hline & $\begin{array}{l}\text { The internal design of the terminal (visual } \\
\text { appearance, attractiveness, etc.) }\end{array}$ & $\mathrm{F} 2$ & 2.81 & 1.16 & $0.675^{*}$ \\
\hline & $\begin{array}{l}\text { The external design of the terminal (visual } \\
\text { appearance, attractiveness, etc.) }\end{array}$ & F3 & 2.91 & 1.15 & $0.635^{*}$ \\
\hline
\end{tabular}




\begin{tabular}{|c|c|c|c|c|c|}
\hline Criteria & Indicators & Code & $\begin{array}{c}\text { Average } \\
\text { rating }(\mathbf{M})\end{array}$ & $\begin{array}{c}\begin{array}{c}\text { Standard } \\
\text { deviation } \\
\text { (SD) }\end{array} \\
\end{array}$ & $\begin{array}{c}\text { Spearman } \\
\text { correlation } \\
\text { coefficient }\end{array}$ \\
\hline \multirow{6}{*}{$\begin{array}{l}\text { Safety and } \\
\text { security }\end{array}$} & $\begin{array}{l}\text { Safety getting on and off the transport mode } \\
\text { (train, bus, taxi, bicycle, etc.) }\end{array}$ & G1 & 3.46 & 0.93 & $0.639 *$ \\
\hline & Safety whilst inside the terminal & G2 & 3.19 & 1.14 & $0.630 *$ \\
\hline & $\begin{array}{l}\text { Feeling secure in the transfer } \& \text { waiting areas } \\
\text { (during the day) }\end{array}$ & G3 & 3.35 & 1.11 & $0.619 *$ \\
\hline & $\begin{array}{l}\text { Feeling secure in the transfer } \& \text { waiting areas } \\
\text { (during the evening/night) }\end{array}$ & G4 & 2.88 & 1.3 & $0.600 *$ \\
\hline & $\begin{array}{l}\text { Feeling secure in the surrounding area of the } \\
\text { terminal }\end{array}$ & G5 & 2.90 & 1.17 & $0.576^{*}$ \\
\hline & Lighting & G6 & 3.69 & 0.99 & $0.624 *$ \\
\hline \multirow{3}{*}{$\begin{array}{l}\text { Emergency } \\
\text { situation } \\
\text { handling }\end{array}$} & Information to improve your sense of security & $\mathrm{H} 1$ & 3.13 & 1.07 & $0.615 *$ \\
\hline & Signposting to emergency exits & $\mathrm{H} 2$ & 3.52 & 1.1 & $0.553 *$ \\
\hline & Location of emergency exits in case of fire & H3 & 3.42 & 1.13 & $0.613 *$ \\
\hline $\begin{array}{l}\text { Overall } \\
\text { satisfaction }\end{array}$ & $\begin{array}{l}\text { Overall score of user satisfaction with the } \\
\text { service in the terminal }\end{array}$ & I & 3.49 & 0.79 & - \\
\hline
\end{tabular}

\subsection{Decision tree outcomes}

Having as goal to increase the interchange performance, as it is perceived by its users, a decision tree was developed to point out the quality decisions that should be made by the interchange managers in order to increase the overall station satisfaction.

The decision tree was developed, using the J48 algorithm and comparing the performance rating of 36 quality indicators (presented in Table 1) and the overall satisfaction of the station rating (Fig. 1). The tree was developed in the open source software WEKA (Waikato Environment for Knowledge Analysis), with pruning value: 0.25 and having as test mode the evaluation on training data.

The developed tree had 51 nodes and 26 leaves (end nodes). In total 89.5397\% (214) of the instances were correctly classified, proving that the tree is highly accurate and the clustering was successfully made (Tsami et al., 2017).

Beginning with the root node that represents the entire dataset, the algorithm splits data into smaller subsets. In that case the root node is the indicator "The surrounding area is pleasant". The root node is the most crucial node in the tree development based on the tree analysis. Also, this is validated in Table 1 that presents the great correlation of this indicator with the overall performance rating.

The tree initially splits the users (instances) in two subsets, those rated the root indicator as below or equal average level $(\leq 3)$ and those that rated it as above average level $(>3)$. The subsets denote the partitions of the original dataset that satisfy specified attribute value tests. For the first subset the next attribute test is linked with the evaluation of the indicator "Information to improve your sense of security", while for the second with the evaluation of attribute "Number and variety of coffee-shops and restaurants". This process continues until all instances in each subset fall in the same class and therefore the tree growing is terminated.

The end nodes of the tree represent the value of the overall performance (from the lowest value (1) to the highest (5)) and the numbers in the parenthesis represent the analogy of the correctly/not correctly classified instances.

Therefore, starting from the root node and following a path that ends in a node with the number 5 , one can address the critical quality indicators that are linked with the highest overall evaluation of the station. Decision makers may then be able to follow the "tree rules" in order to increase the performance of their stations with the minimum number of interventions (as only the most critical quality indicators may be affected and not all).

The tree developed in terms of this study had 11 paths leading to a perception of satisfaction (overall satisfaction rating $=4$ ) and two paths leading to the best possible satisfaction rating $(=5)$.

Both these paths, linked with the highest evaluation score $(=5)$, deal with indicators that improve the general perception of quality in the interchange (number and variety of coffee-shops and restaurants, 
external design of the interchange (visual appearance, attractiveness, etc.), temperature, shelter from rain and wind, ventilation, air conditioning).

According to the tree, if we want to achieve the highest overall evaluation of the station performance, we need to have an evaluation higher than 3 for the indicator "The surrounding area is pleasant", higher than 2 for the indicators "Number and variety of coffee-shops and restaurants" and "The external design of the interchange (visual appearance, attractiveness, etc.)", higher than 4 for the indicators "Temperature, shelter from rain and wind, ventilation, air conditioning", "Ease of movement due to number of people inside the interchange" and "The surrounding area is pleasant" and higher than 3 for the indicator "Information and assistance provided by staff (e.g. at customer information points)".

The same overall score (=5) can be achieved alternatively following the second path, that requires an evaluation higher than 3 for the indicator "The surrounding area is pleasant", higher than 2 for the indicators "Number and variety of coffee-shops and restaurants" and "The external design of the interchange (visual appearance, attractiveness, etc.)", higher than 4 for the indicator "Temperature, shelter from rain and wind, ventilation, air conditioning" and equal or lower than 3 for the indicator "Ticket purchase (ticket offices, ticket machines, etc.)".

Although there are two paths leading to the highest score for the overall performance assessment of the hub, the first one is preferable to be followed due to the highest number of correctly classified instances (11). Apart from that, the main difference between the two paths is that the first includes more indicators and is even more focused on the perceived hospitability of the interchange facilities and the quality of offered services.

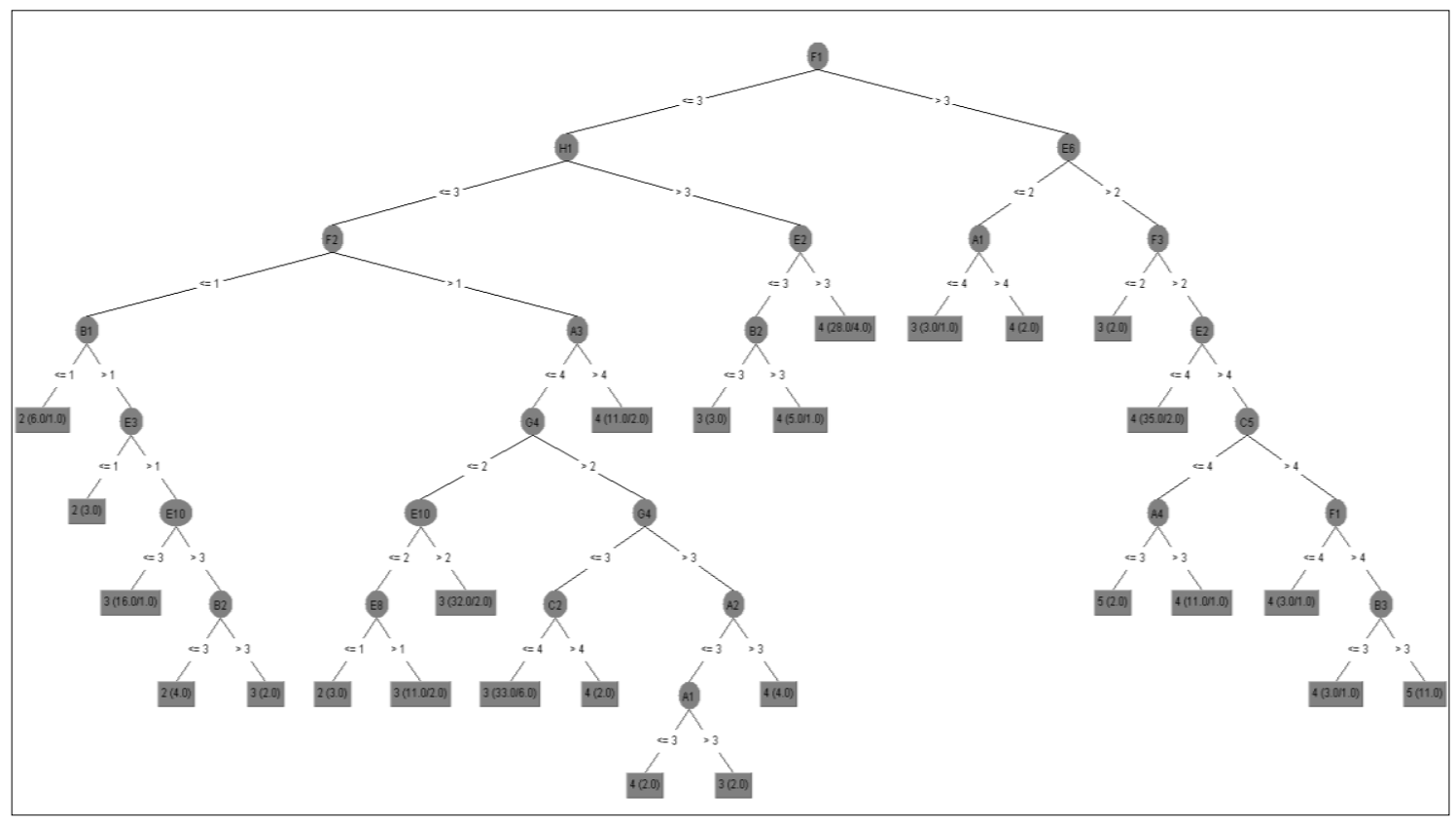

Figure 1. Decision tree development (Tsami et al., 2017)

\subsection{Discussion}

The starting node in the two selected tree paths is "Surrounding area". This indicator has been attributed an average rating of 2.93 and showed the highest correlation with overall satisfaction (Spearman 0.674). According to both paths, in order to achieve the highest overall satisfaction (5), the threshold value of "Surrounding area" is 3, in the first occurrence of the indicator as a node and 4 in the second. So, it is expected that the overall satisfaction is rated lower, which is true, as the average value of the responses is estimated to 3.49. Same observation stands for the indicator concerning the interior of the station "Temperature, shelter from rain and wind, ventilation, air conditioning". Requirement for reaching the highest satisfaction, is that this indicator receives a rating above 4 . In fact, this indicator has been attributed the value of 3.58, and with a high correlation with the overall satisfaction (Spearman 0.622), it justifies the lower rate of the latter.

"External design" is rated 2.91, which is also reflected to the actual overall satisfaction, as there is a high correlation between the two indicators (Spearman 0.635). However, according to the paths, if the 
previously mentioned indicators have a higher rating, the overall satisfaction is not affected negatively. Thus, "External design" is not required to have a high rating in order to achieve high overall satisfaction.

The two indicators "Ease of movement" and "Information and assistance by the staff" have a lower correlation with the overall satisfaction, as compared to the previous indicators. It is required that they get a rating above 4 and 3, respectively, to lead to a high overall satisfaction. From the responses, the first received a rating below the threshold (3.64) and the second above (3.59).

"Ticket purchasing" has a low correlation with the overall satisfaction (0.416). Although it received a rating 4.01, it did not lead to the highest overall satisfaction rating (5 or 4).

\section{Conclusions}

The goal of this paper was to investigate the satisfaction level of the Riga International Coach Terminal on different aspects that define the design, operation and services of sustainable urban transport interchanges. To this end, an on-site face to face and online questionnaire survey was conducted and useful feedback was gathered from 239 users about their habits, preferences and overall satisfaction.

For the achievement of high customer satisfaction, a decision tree approach was proposed, through the development of a classification tree with the use of the algorithm C4.5. It was observed that the surrounding area atmosphere is the most important indicator for users (parent node of the tree). Both paths that have the highest evaluation scores deal with indicators that improve the general perception of quality in the interchange (number and variety of coffee-shops and restaurants, external design of the interchange (visual appearance, attractiveness, etc.), temperature, shelter from rain and wind, ventilation, air conditioning).

The proposed methodology can facilitate decision makers understand the users' perspectives and predict the most important factors contributing to their satisfaction, by studying the developed decision tree, and act accordingly to accommodate their needs.

\section{Acknowledgements}

This paper is based on the research and work that has been conducted in the framework of the ALLIANCE project (http://alliance-project.eu/), which has received funding from the European Union's Horizon 2020 Research and Innovation Programme. The authors would like to thank both the consortium of the project and the European Commission.

\section{References}

1. ADB (2015) Improving interchanges: Introducing best practices on multimodal interchange hub development in the People's Republic of China. ASIAN DEVELOPMENT BANK.

2. Acharia, T., Yang, I., Lee, D. (2015) Application of J48 Decision Tree for the Identification of Water Bodies Using Landsat 8 OLI Imagery. In: 2nd International Electronic Conference on Sensors and Applications. Online.

3. Ahishakiye, E., Omulo, E., Taremwa, D., Niyonzima, I. (2017) Crime Prediction Using Decision Tree (J48) Classification Algorithm, International Journal of Computer and Information Technology, 6(3): 188-195.

4. Allmuali, H., Kaneda, S., Akiba, Y. (2002) Development and Applications of Decision Trees. In: Expert Systems, Vol.1, Academic Press.

5. Breiman, L., Friedman, J H., Olshen, R.A., and Stone, C.J. (1984) Classification and regression trees. Monterey, CA: Wadsworth.

6. de Ona, J., de Ona, R., Calvo, F. (2011) A Classification Tree Approach to Identify Key Factors of Transit Service Quality. Expert Systems with Applications, 39: 11164-11171.

7. de Ona, J., de Ona, R., Lopez, G. (2016) Transit Service Quality Analysis and Decision Trees: A Step Forward to Personalized Marketing in Public Transportation. Transportation, 43(5): 725-747.

8. Dota, M., Cugnasca, C., Barbosa, D. (2015) Comparative Analysis of Decision Tree Algorithms on Quality of Water Contaminated with Soil. Ciencia Rural, 45(2): 267-273.

9. European Commission (2001) White Paper "European transport policy for 2010: Time to decide". CEC.

10. Ewing, R., Schmid, T., Killingsworth, R., Zlot, A. and Raudenbush, S. (2008) Relationship between urban sprawl and physical activity, obesity and morbidity. In: J. M. Marzluff, E. Shulenberger, W. 
Endlicher, M. Alberti, G. Bradley, C. Ryan, U. Simon and C. ZumBrunnen (Eds). New York: Urban Ecology, 567-582.

11. Gao, W., Tang, W., Wang, X. (2013) Application of an Improved C4.5 Algorithm in Performance Analysis. Applied Mechanics and Materials, 380-384: 1681-1684.

12. Kapoor, P., Rani, R. (2015) Efficient Decision Tree Algorithm Using J48 and Reduced Error Pruning. International Journal of Engineering Research and General Science, 3(3): 1613-1621.

13. Kaur, G., Chhabra, A. (2014) Improved J48 Classification Algorithm for the Prediction of Diabetes. International Journal of Computer Applications, 98(22): 13-17.

14. Kumar, A. (2014) Design and Applications of Decision Trees. International Journal of Computer Science Trends and Technology, 2(4): 94-98.

15. Maleki-Entezari, R., Rezaei, A., Minaei-Bidgoli, B. (2009) Comparison of Classification Methods Based on the Type of Attributes and Sample Size. Journal of Convergence Information Technology, 4(3): 94-102.

16. Nathanail, E., Adamos, G., Tsami, M. (2016) Why Interchanges? Understanding intermodality, In: A.Monzon and F.d.Ciommo (eds), CITY-HUBs: Sustainable and Efficient Urban Transport Interchanges, 13-36.

17. Patil, T., Sherekar, S. (2013) Performance Analysis of Naive Bayes and J48 Classification Algorithm for Data Classification. International Journal of Computer Science and Applications, 6(2): 256-261.

18. Quinlan, (1993) C4.5: Programs for machine learning. San Francisco: Morgan Kaufmann.

19. RD PAD, (2017) The economic profile of Riga 2017. Riga: Riga city council Development department.

20. Song, Y., Lu, Y. (2015) Decision Tree Methods: Applications for Classification and Prediction. Shanghai Archives of Psychiatry, 27(2): 130-135.

21. Tsami, M., Nathanail, E. (2016) Guidance Provision for Increasing Quality of Service of Public Transport. In: 16th Conference on Reliability and Statistics in Transportation and Telecommunication. Riga, Latvia.

22. Tsami M., Budilovich (Budiloviča) E., Magginas V., Adamos G., Yatskiv (Jackiva) I. (2018) Assessing the Design and Operation of Riga's International Coach Terminal. In: Kabashkin I., Yatskiv I., Prentkovskis O. (eds) Reliability and Statistics in Transportation and Communication. RelStat 2017. Lecture Notes in Networks and Systems, vol.36. Springer, 497-506

23. Vaadaala, V., Rao, R., Rao, V. (2013) Classification of Web Services Using JForty Eight. International Journal of Electronics Communication and Computer Engineering, 4(6): 181-184.

24. Vuchic, V. R. (2005) Urban Transit: Operations, Planning, and Economics. New York: John Wiley.

25. Yan, N., Ju, W., Fang, H., Sato, R. (2015) Application of J48 Decision Tree Classifier in Emotion Recognition Based on Chaos Characteristics. In: International Conference on Automation, Mechanical Control and Computational Engineering. Changsha, China. 